\title{
Immunoendocrine responses of male spinal cord injured athletes to 1-hour self-paced exercise: Pilot study
}

\author{
Judith E. Allgrove, PhD; ${ }^{*}$ Mark Chapman, MSc; ${ }^{1}$ Tatiana Christides, MD; ${ }^{1}$ Paul M. Smith, PhD $^{\mathbf{2}}$ \\ ${ }^{1}$ School of Science, University of Greenwich, Kent, United Kingdom; ${ }^{2}$ Cardiff Metropolitan University, Cardiff, United \\ Kingdom
}

\begin{abstract}
This study examined the effect of a $1 \mathrm{~h}$, self-paced handcycling time trial on blood leukocytes, mucosal immunity, and markers of stress in paraplegic athletes. Nine male paraplegic athletes (spinal injury level thoracic 4-lumbar 2) performed $1 \mathrm{~h}$ of handcycling exercise on a standard $400 \mathrm{~m}$ athletics track. Heart rate (HR) was measured continuously during exercise, and a retrospective rating of perceived exertion (RPE) was obtained immediately after. Venous blood and saliva samples were collected immediately before exercise (Pre-Ex), after exercise (End-Ex), and $1 \mathrm{~h}$ postexercise (1-h Post). The athletes completed mean $+/$ - standard error of mean $22.4+/-1.1 \mathrm{~km}$ cycling at HR $165+/-2$ beats/min, RPE $15+/-1$, and blood lactate $7.9+/-2.5 \mathrm{mmol} / \mathrm{L}$. Total leukocytes increased $72 \%$ and neutrophils increased 74\% End-Ex; both remained elevated at 1-h Post (both $p<0.05$ ). Lymphocytes increased 53\% and natural killer cells increased $175 \%$ End-Ex (both $p<0.05$ ), but returned to near baseline levels 1-h Post. Increases $(p<0.05)$ were observed End-Ex in alpha-amylase activity $(p<0.05)$, which returned to baseline at 1-h Post, but there was no significant change in saliva flow rate, salivary immunoglobulin A, or cortisol. These data confirm that $1 \mathrm{~h}$ of handcycling exercise elevated circulating leukocytes but had a minimal effect on mucosal immunity. These changes appear to be associated with alpha-amylase rather than cortisol.
\end{abstract}

Key words: exercise, handcycling, immunoendocrine response, leukocytes, natural killer cells, neutrophils, salivary immunoglobulin A, spinal cord injury, stress, time trial.

\section{INTRODUCTION}

The relationship between exercise and immune function in nondisabled individuals appears to be determined by exercise intensity and duration [1]. Prolonged, strenuous exercise can result in a temporary decrease in certain aspects of immune function lasting 2 to 24 hours, where changes in leukocyte numbers and functional capacities are observed, and may lead to an increase in infection risk. In contrast, regular moderate exercise has been associated with a reduced risk of infection compared with a sedentary lifestyle [2]. The effects of exercise on the immune system are largely influenced by the central nervous system and resultant changes in stress hormones, including cortisol and adrenaline, and alterations in the pro/anti-inflammatory cytokine balance [3].

\footnotetext{
Abbreviations: 1-h Post $=1$ hour postexercise, End-Ex $=$ after exercise, $\mathrm{HR}=$ heart rate, IgA = immunoglobulin A, IL = interleukin, $\mathrm{NK}=$ natural killer, Pre-Ex $=$ before exercise, $\mathrm{RPE}=$ rating of perceived exertion, $\mathrm{SCI}=$ spinal cord injury, $\mathrm{SEM}=$ standard error of mean, s-IgA = salivary IgA, SNS = sympathetic nervous system.

*Address all correspondence to Dr. Judith Allgrove; School of Science, University of Greenwich, Central Avenue, Chatham Maritime, Kent, ME4 4TB, UK; +0044-20-8331-8241; fax: 0044-20-8331-9805. Email: J.E.Allgrove@gre.ac.uk http://dx.doi.org/10.1682/JRRD.2011.06.0105
} 
It is widely recognized that individuals with a spinal cord injury (SCI) experience recurrent infections, specifically of the respiratory system, urinary tract, and skin [45], and some evidence suggests that this susceptibility to infection is partly associated with immune dysfunction [6-9]. Alterations in natural killer (NK) cell number and cytotoxicity, $\mathrm{T}$ cell function and activation, macrophage phagocytosis, levels of interleukin (IL)-2 and -6, the soluble IL-2R receptor, and intracellular adhesion molecules have been reported [4]. Decentralization of the autonomic nervous system has been speculated as a likely cause of this compromised status, the extent of which is dependent on the neurological level and completeness of the injury [10], although the level of physical activity, diet [11], medication, and chronic stress/depression are also likely to play a role.

The pursuit of recreational activity and/or competitive sport by individuals with SCI is extremely important and can have a profound, positive influence on an individual's quality of life [12]. In this context, handcycling has emerged as an extremely efficient mode of ambulation that can be employed on a daily basis [13] and holds important applications in the field of clinical rehabilitation [14]. It is clear that the metabolic demand associated with moderate intensity handcycling facilitates sufficient energy expenditure to offer some protection against the onset of chronic and progressive conditions such as cardiovascular disease [15]. However, relatively little is known about the immunoendocrine responses of individuals with SCI during moderate intensity endurance activity. Given the immune dysfunction and increase in infection incidence typically reported in this population, understanding the effects of exercise upon immune function is of considerable importance. Furthermore, upper-body exercise has generally been reported to elicit a higher stress hormone response than lower-body exercise at the same relative intensity [16], which may also affect the immune response associated with prolonged physical exertion. Previously, studies have reported increases in circulating NK cell number and cytotoxicity (part of innate immunity) in sedentary SCI individuals following electrically stimulated cycling [17] and 20 min of orthotic gait exercise [18]. More strenuous and prolonged upper-body exercise ( $>60 \mathrm{~min}$ ) has been shown to significantly decrease the number of NK cells and their cytotoxicity postexercise [19], but this compromised response did not occur in nondisabled athletes [20]. It was proposed that these differences were likely mediated by changes in cortisol [19] and prostaglandin E2 in the SCI group [20].

Research associated with the effects of exercise on the immune system in SCI individuals has largely focused on the NK cell response [17-20]. Mucosal immunity, of which immunoglobulin A (IgA) is the predominant antibody, is considered the first line of defense against invading pathogens entering the respiratory tract; previous research has shown a link between this antibody and upper respiratory tract illness [21-22]. Furthermore, acute strenuous exercise has been shown to decrease salivary IgA (s-IgA), which might lead to a greater risk of infection [23], whereas some evidence suggests that moderate or short duration exercise may increase s-IgA, leading to a reduced risk of infection [24]. In one recent study, s-IgA secretion rate was shown to increase following $60 \mathrm{~min}$ of treadmill exercise in elite wheelchair athletes, and a greater increase was observed in people with tetraplegia than in people with paraplegia or in individuals without SCI [25].

As stated above, changes in immune function with exercise have been attributed to alterations in stress hormone responses. While salivary cortisol has been accepted as a reliable and valid marker of levels circulating in blood, catecholamines measured in saliva are less stable and do not provide a valid reflection of plasma concentrations [26]. Therefore, $\alpha$-amylase is used as a preferred salivary surrogate marker of sympathetic nervous system (SNS) activity, since its activity has been shown to correlate with noradrenaline concentrations [27]. Given the paucity of data related to immunoendocrine responses to exercise in SCI and in particular to handcycling, the aim of this study was to examine and quantify the acute effect of a $1 \mathrm{~h}$, self-paced handcycling time trial on mucosal immunity, the concentration of circulating leukocytes, and stress hormone responses.

\section{METHODS}

\section{Participants}

Nine physically active male athletes with SCI volunteered to complete a $1 \mathrm{~h}$, self-paced handcycling time trial. The average age, stature, and mass of the participants was mean \pm standard error of mean (SEM) $44 \pm$ $2 \mathrm{yr}, 1.77 \pm 0.10 \mathrm{~m}$, and $78.6 \pm 2.3 \mathrm{~kg}$, respectively. All nine participants were members of the U.K. Handcycling Association and frequently engaged in the sport. All 
participants had sustained a traumatic SCI (range from thoracic 4 to lumbar 2), and all but one were classified as $\mathrm{H} 2$ division handcyclists; the other rider was classified as H4. The characteristics related to their injury, handcycling classification, and physical activity levels are presented in Table 1.

\section{Exercise Task}

The study took place on a $400 \mathrm{~m}$ athletics track at Stoke Mandeville Stadium on a warm $\left(25^{\circ} \mathrm{C}\right)$ and dry (49\% humidity) day at the end of May. Following an initial $10 \mathrm{~min}$, self-prescribed warm-up, participants completed a $1 \mathrm{~h}$, self-paced time trial using a counter-flow pattern. Participants cycled in the conventional (counterclockwise) direction using the three inside lanes of the track and cycled in the opposite (clockwise) direction using the three outside lanes. To facilitate changes in direction, a $6 \mathrm{~m}$ turning circle was arranged in the $100 \mathrm{~m}$ starting area of the track, and all participants were required to cycle in a clockwise direction when using the turning circle. During the time trial, participants were instructed to complete as much distance as possible, and participants started their $1 \mathrm{~h}$ time trial at 3 min intervals. The purpose of using a counterflow pattern was to equilibrate the extent of the lateral (centripetal) forces experienced by the participants, especially in the neck when the athletes negotiated the tight corners of the track at speed. The participants were instructed to use the turning circle after every 10 laps to change direction and then completed the next 10 laps in the opposite direction. This pattern continued until each participant had completed the $1 \mathrm{~h}$

Table 1.

Individual participant characteristics related to injury, handcycling classification, and training frequency.

\begin{tabular}{|c|c|c|c|c|}
\hline No. & $\begin{array}{c}\text { Time } \\
\text { Injured } \\
\text { (yr) }\end{array}$ & $\begin{array}{l}\text { Injury } \\
\text { Level }\end{array}$ & $\begin{array}{l}\text { Handcycling } \\
\text { Classification }\end{array}$ & $\begin{array}{c}\text { Training } \\
\text { (times/wk) }\end{array}$ \\
\hline 1 & 26 & $\mathrm{~T} 4$ & $\mathrm{H} 2$ & 5 \\
\hline 2 & 15 & T4/T5 & $\mathrm{H} 2$ & 5 \\
\hline 3 & 3 & $\mathrm{~T} 12^{*}$ & $\mathrm{H} 2$ & 2 \\
\hline 4 & 8 & T6 & $\mathrm{H} 2$ & 2 \\
\hline 5 & 36 & T10/T11 & $\mathrm{H} 2$ & 3 \\
\hline 6 & 29 & $\mathrm{~T} 4^{*} / \mathrm{L} 1^{*} / \mathrm{L} 2^{*}$ & $\mathrm{H} 2$ & 3 \\
\hline 7 & 19 & $\mathrm{~T} 12^{*}$ & $\mathrm{H} 4$ & 4 \\
\hline 8 & 3 & $\mathrm{~T} 10$ & $\mathrm{H} 2$ & 3 \\
\hline 9 & 3 & $\mathrm{~T} 12^{*}$ & H2 & 2 \\
\hline
\end{tabular}

time trial. To track variations in average speed, we recorded split times for each participant at the end of each set of 10 laps.

\section{Collection of Saliva Samples}

Samples of saliva were collected after the warm-up before exercise (Pre-Ex), upon immediate completion of the time trial after exercise (End-Ex), and after $1 \mathrm{~h}$ of passive recovery postexercise (1-h Post). The collection was made with the participants seated/kneeling in their respective handbikes, leaning forward, and tilting their heads down. After sitting quietly for a few minutes, they were instructed to swallow to empty the mouth before an unstimulated whole saliva sample was collected for 3 min into a preweighed vial. Care was taken to allow saliva to dribble into the collecting tubes with minimal orofacial movement. Samples were immediately stored on ice and subsequently taken to the laboratory for storage within $4 \mathrm{~h}$ of collection. Before storage, the saliva samples were weighed to the nearest $10 \mathrm{mg}$, after which the saliva was centrifuged at $1,500 \mathrm{~g}$ for $15 \mathrm{~min}$, and the remaining supernatant was removed and stored at $-80^{\circ} \mathrm{C}$ until subsequent analysis.

\section{Collection of Blood Samples}

Serial samples of venous blood $(10 \mathrm{~mL})$ were collected Pre-Ex, End-Ex, and 1-h Post from a superficial vein in the antecubital fossa using sterile, repetitive venepuncture. Blood was dispensed into two Vacutainers (Becton Dickson; Oxford, United Kingdom), one containing $\mathrm{K}_{3}$ EDTA and another containing heparin. Samples were immediately stored on ice until analysis was performed within $4 \mathrm{~h}$ of collection.

\section{Distance Covered, Heart Rate, and Rating of Perceived Exertion}

In conjunction with the dimensions of the standard $400 \mathrm{~m}$ track, we estimated that each participant covered $412 \mathrm{~m}$ and $440 \mathrm{~m}$ during each lap completed in a counterclockwise and clockwise direction, respectively. An additional $20 \mathrm{~m}$ was added to the participants' distances each time they used the turning circle to achieve a change direction. Subsequently, cumulative distances for all participants were calculated based on the number of laps completed. Prior to the time trial, all participants were fitted with a recordable heart rate (HR) monitor (Polar RS4000; Kemple, Finland), and HR was recorded at $5 \mathrm{~s}$ intervals throughout exercise. Finally, having completed the time trial, participants were asked to provide a 
retrospective rating of perceived exertion (RPE) using the 6-20 Borg scale. The participants were informed that this subjective rating should typically represent the average effort they experienced during the entire $1 \mathrm{~h}$ time trial.

\section{Saliva Analysis}

Saliva volume was estimated by weighing each collection vial to the nearest milligram, and the saliva density was assumed to be $1.0 \mathrm{~g} \cdot \mathrm{mL}^{-1}$. Saliva flow rate (milliliters per minute) was determined by dividing the volume of saliva by the collection time. After thawing, s-IgA, cortisol, and $\alpha$-amylase activity were determined using commercially available enzyme linked immunosorbent assay kits (Salimetrics; Newmarket, United Kingdom). Salivary osmolality was analyzed using a cryoscopic (freezing-point depression) osmometer (calibrated with deionized water and $300 \mathrm{mOsmol} / \mathrm{kg} \mathrm{NaCl}$ solution). The secretion rate of s-IgA (micrograms per minute) was calculated by multiplying the s-IgA concentration by the saliva flow rate.

\section{Blood Analysis}

Heparinized blood was used to measure blood lactate concentration End-Ex using a fully automated system (Biosen 5030, EKF Industrie-Elektronik GmbH; Barleben, Germany). The $\mathrm{K}_{3}$ EDTA blood was used for hematological analysis, including hemoglobin and total and differential leukocyte counts using a cell counter (60+ Pentra, Horiba; Kyoto, Japan) and hematocrit by centrifugation. NK cell concentration was determined according to cell surface molecules using monoclonal antibodies directed against key NK cell markers: CD16 and CD56. The lymphocyte population was indentified using anti-CD45 monoclonal antibody conjugated to $\mathrm{Cy} 5$ and integrated to establish the NK cell population using dual staining with anti-CD56 and CD16 monoclonal antibody conjugated to phycoerythrin (Beckman Coulter; Paris, France). After an initial 10 min incubation in the dark, cells were lysed using VersaLyse (Beckman Coulter) and then vortexed. Following a further 10 min period of incubation in the dark, labeled cells were analyzed by flow cytometry using an Epics XL.MCL (Beckman Coulter). CD16/CD56 positive events were counted in the lymphocyte population (based on CD45 positivity and side scatter morphology). Absolute counts were generated using flow-count beads (Beckman Coulter).

\section{Statistical Analyses}

All data were processed using Microsoft Excel (Microsoft Corporation; Redmond, Washington), and all statistical analyses were conducted using SPSS (IBM; Armonk, New York). Mean ( \pm SEM) values were calculated for all variables. Interclass Pearson product moment correlation coefficients were calculated between the individual time trial distances completed and the respective concentration of all immunoendocrine parameters measured Pre-Ex, End-Ex, and 1-h Post to determine if a relationship existed between the performance capacity and immunoendocrine status of the participants. Changes in the concentrations of the immunoendocrine parameters across time were analyzed using separate, repeated measures one-way analysis of variance tests with Holm-Bonferroni corrections applied where appropriate. Significance was accepted at the 95 percent level of confidence ( $p \leq 0.05$ ), and where a significant main effect was observed multiple post hoc, (Bonferroni) pairwise comparisons were made to specifically identify where differences existed.

\section{RESULTS}

\section{Distance Covered, Heart Rate, Blood Lactate Concen- tration, and Rating of Perceived Exertion}

The respective experience and training status of the participants varied considerably. During the $1 \mathrm{~h}$ time trial, participants completed an average distance of $22.4 \pm$ $1.1 \mathrm{~km}$ (range: 17.9-27.2 km). On average, the participants' HR was $165 \pm 2$ beats/min, End-Ex blood lactate was $7.9 \pm 2.5 \mathrm{mmol} / \mathrm{L}$, and time trial $\mathrm{RPE}$ was 15 [1].

Table 2.

Individual values of time trial indices.

\begin{tabular}{cccccc}
\hline No. & $\begin{array}{c}\text { Distance } \\
\mathbf{( k m )}\end{array}$ & $\begin{array}{c}\text { Average HR } \\
\text { (beats/min) }\end{array}$ & $\begin{array}{c}\text { Peak HR } \\
\text { (beats/min) }\end{array}$ & $\begin{array}{c}\text { B[La]end } \\
(\mathbf{m m o l} / \mathbf{L})\end{array}$ & $\begin{array}{c}\text { TT RPE } \\
(\mathbf{6}-\mathbf{2 0} \text { Borg) }\end{array}$ \\
\hline 1 & 27.2 & 165 & 170 & 12.5 & 13 \\
2 & 26.0 & 176 & 179 & 10.0 & 15 \\
3 & 20.7 & 176 & 181 & 8.4 & 13 \\
4 & 17.9 & 158 & 161 & 5.8 & 17 \\
5 & 21.6 & 160 & 168 & 7.4 & 15 \\
6 & 24.2 & 168 & 173 & 3.9 & 16 \\
7 & 24.7 & 158 & 166 & 7.6 & 15 \\
8 & 19.5 & 158 & 172 & 6.2 & 13 \\
9 & 20.3 & 166 & 172 & 8.9 & 19 \\
Mean \pm SEM & $22.4 \pm 1$ & $165 \pm 2$ & $171 \pm 2$ & $7.9 \pm 2.5$ & $15 \pm 1$ \\
\hline B[La]end = blood lactate concentration, HR = heart rate, RPE = rating of per- \\
ceived exertion, SEM = standard error of mean, TT = time trial. \\
\hline \hline
\end{tabular}


Table 2 summarizes the individual distance covered, heart rate, blood lactate concentration, and RPE values for the time trial.

\section{Salivary Measures}

Alpha-amylase activity and salivary osmolality increased significantly $(p<0.05)$ from Pre-Ex to End-Ex, but no changes $(p>0.05)$ were observed in saliva flow rate, s-IgA concentration and secretion rate, osmolality, or cortisol following exercise (Table 3).

\section{Blood Measures}

Total leukocyte count increased End-Ex and remained elevated at 1 -h Post $(p<0.05)$, and a similar pattern existed for neutrophils $(p<0.05)$. Compared with resting values, the concentration of lymphocytes increased during exercise $(p<0.05)$ but had generally returned to near baseline levels at 1 -h Post. NK cells increased $(p<0.05)$ at End-Ex, but had also returned close to baseline values at 1 -h Post (Table 4$)$. Strong $(p<0.01)$ positive correlation coefficients were observed between time trial distance and white blood cell count $(r=0.79)$ and neutrophil count $(r=0.78)$, though no other correlation coefficients of the data approached significance.

\section{DISCUSSION}

The completion of a $1 \mathrm{~h}$, self-paced handcycling time trial acutely increased the circulating concentration of leukocytes but did not influence mucosal immunity. Alpha-amylase activity increased End-Ex, but cortisol remained unchanged. There are limited data regarding the effect of exercise in athletes with SCI in the context of both cell-mediated and mucosal immune responses. This is relevant because immune dysfunction has been reported in individuals with SCI and SCI is associated with an increased incidence of respiratory and urinary tract infections [4-5].

Saliva flow and composition are under strong autonomic control and can be modified significantly during exercise where SNS activity is enhanced. Indeed, significant changes in s-IgA in nondisabled athletes have been previously observed following prolonged exercise (>90 min) [28-29] or high intensity exercise [30-33], most likely via alterations in the trancytosis of s-IgA across the epithelial lining [34] or through the production of s-IgA by the Blymphocytes that reside in the submucosa [35]. However,

Table 3.

Mean \pm standard error of mean values of salivary parameters in response to handcycling.

\begin{tabular}{lcccc}
\hline \multicolumn{1}{c}{ Parameter } & Pre-Ex & End-Ex & 1-h Post & p-Value \\
\hline Saliva flow rate (mL/min) & $1.4 \pm 0.2$ & $1.6 \pm 0.3$ & $1.7 \pm 0.3$ & $>0.05$ \\
Salivary osmolality (mOsmol/kg) & $77 \pm 7$ & $111 \pm 12^{*}$ & $73 \pm 5$ & $>0.05$ \\
[s-IgA] (mg/L) & $127.8 \pm 10$ & $212.9 \pm 78.8$ & $134.6 \pm 20.6$ & $>0.05$ \\
s-IgA: Osmolality & $1.7 \pm 0.1$ & $1.9 \pm 0.7$ & $92 \pm 28$ & $>0.05$ \\
s-IgA secretion rate ( $\mu$ g/min) & $103 \pm 13$ & $153 \pm 54$ & $3.6 \pm 0.8$ & $>0.05$ \\
[Cortisol] (nmol/L) & $4.9 \pm 0.5$ & $9.5 \pm 3.2$ & $119 \pm 25$ & $<0.05$ \\
$\alpha$-amylase activity (U/min) & $158 \pm 47$ & $281 \pm 72^{*}$ & 0.05 \\
\hline
\end{tabular}

${ }^{*}$ Significantly higher than Pre-Ex $(p<0.05)$.

1 -h Post = 1 hour postexercise, End-Ex = after exercise, Pre-Ex = before exercise, s-IgA = salivary immunoglobulin A.

Table 4.

Mean \pm standard error of mean values of blood-related parameters in response to handcycling.

\begin{tabular}{|c|c|c|c|c|}
\hline Parameter & Pre-Ex & End-Ex & 1-h Post & $p$-Value \\
\hline$\overline{\text { Hemoglobin }(\mathrm{g} / \mathrm{L})}$ & $171 \pm 7$ & $164 \pm 6$ & $165 \pm 6$ & $>0.05$ \\
\hline Hematocrit (\%) & $46.0 \pm 1.1$ & $47.1 \pm 1.2$ & $46.7 \pm 1.1$ & $>0.05$ \\
\hline Leukocytes $\left(\times 10^{9} / \mathrm{L}\right)$ & $5.4 \pm 0.6$ & $9.3 \pm 0.6^{*}$ & $11.9 \pm 2.1^{*}$ & $<0.05$ \\
\hline Lymphocytes $\left(\times 10^{9} / \mathrm{L}\right)$ & $1.5 \pm 0.1$ & $2.3 \pm 0.3^{*}$ & $1.3 \pm 0.1$ & $<0.05$ \\
\hline NK cells $\left(\times 10^{9} / \mathrm{L}\right)$ & $0.05 \pm 0.01$ & $0.11 \pm 0.03^{*}$ & $0.03 \pm 0.01$ & $<0.05$ \\
\hline
\end{tabular}

${ }^{*}$ Significantly higher than Pre-Ex $(p<0.05)$.

1-h Post $=1$ hour postexercise, End-Ex = after exercise, NK = natural killer, Pre-Ex = before exercise. 
no significant change $(p>0.05)$ in s-IgA levels was observed following the $1 \mathrm{~h}$ time trial in the current study. These findings are in contrast to a previous study [25], which reported a significant increase in s-IgA secretion rate following $60 \mathrm{~min}$ exercise in elite wheelchair athletes, with a greater response observed in those with tetraplegia. The differences in the s-IgA responses in tetraplegia were attributed to sympathetic reflex activity occurring during exercise because of the lack of centrally mediated sympathetic control in these individuals. Saliva flow rate was also unaffected during the time trial in the current study, and plasma volume remained the same despite an increase in osmolality, suggesting our participants remained well hydrated throughout [36]. All participants had sustained a traumatic SCI and could only engage the relatively small musculature of the upper body during handcycling. Even though they exercised at a heavy intensity, the volume of work or physiological stress may not have been comparable to that experienced in other studies, which might account for the discrepancies observed. Additionally, owing to the preliminary nature of this study, we are unable to conclude whether it was the injury itself that affected the response and/or the unique mode of exercise. Nevertheless, because both s-IgA and saliva flow rate are important in mucosal defense, we can conclude that this aspect of immune status was unaffected by handcycling in our group of athletes with SCI.

Despite no significant effect of handcycling on mucosal immunity, the time trial elicited significant increases in circulating concentrations of leukocytes, neutrophils, lymphocytes, and NK cells, though considerable interindividual variations were observed. Levels of neutrophils remained elevated at 1-h Post, and have consistently been shown to remain elevated for between 2 to $24 \mathrm{~h}$ thereafter in nondisabled individuals [37], with the magnitude thought to be dependent on the exercise intensity and/or duration [38]. These effects are likely a result of demargination of cells adhered to the endothelial cells of the vasculature through the release of catecholamines or through a delayed release of neutrophils from the bone marrow associated with a rise in circulating cortisol [39]. However, some aspects of the neutrophils' functional capacity may be compromised [3]. Lymphocytes and NK cells both increased at End-Ex but returned to baseline values at 1-h Post. A similar profile for NK cells was observed following $2 \mathrm{~h}$ of arm crank ergometry in individuals with SCI [20]. Lower resting levels of NK cells in SCI than in nondisabled individuals were also reported, which might be indicative of acquired immunosuppression. The functional capacity of the leukocytes was not examined in the present study, though the increase in leukocytes suggests the $1 \mathrm{~h}$, self-paced time trial led to a transient enhancement of this aspect of immunity. Note the clinical significance of these findings is unknown, and future studies should address how the immune changes in response to handcycling exercise relate to subsequent rates of infection.

An interesting find in this investigation was the significant positive correlations between resting levels of leukocytes and neutrophils and the distance completed during the time trial. Few data exist to support differences in resting immune function with training status [40]. Nieman et al. reported elevated NK cell activity in elite rowers compared with controls [41]. However, lower levels of neutrophil function have been reported in endurance-trained runners following 3 weeks of intensified training [42]. Our findings indicate that an enhanced aspect of basal immune function occurred with training status, which might confer some resistance to infection.

Changes in immune function observed during exercise have been attributed largely to alterations in stress hormones, including the release of cortisol and catecholamines [3]. In the current study, $\alpha$-amylase activity was used as a surrogate marker of SNS activity. Levels of $\alpha$-amylase increased at End-Ex but returned to baseline at 1-h Post, suggesting that the metabolic demands of the handcycling time trial significantly increased SNS activity. In contrast, salivary cortisol levels remained unchanged. Typically, increases in cortisol are observed at exercise intensities above 65 percent maximal oxygen consumption $\left(\mathrm{VO}_{2 \max }\right)$ and after a lag period of $45 \mathrm{~min}$ in nondisabled individuals [43]. This suggests that our participants might not have exercised at a sufficiently high intensity to evoke a cortisol response, though the applied setting of this study prevents us from confirming or refuting this speculation. Alternatively, it might be the mode of exercise, (i.e., upper vs lower body) or possibly the SCIs themselves that prevented the typical changes that are observed. In addition, cortisol is known to exhibit a diurnal variation, which peaks $45 \mathrm{~min}$ after awakening and then decreases throughout the day [44]. Since the exercise in the present study commenced at 11:00 a.m., an increase in cortisol may have been masked by this diurnal variation. Leicht et al. also reported a significant increase in $\alpha$-amylase activity following 60 min of treadmill exercise in both SCI and non-SCI elite wheelchair athletes [25]; however, cortisol was not measured in this study, so a comparison cannot be made. Taken together, it seems plausible that the leukocytosis 
observed was due to an increase in SNS activity rather than the stimulation of the hypothalamic-pituitary-adrenal axis, which agrees with previous findings [45]. It is also worth noting the $\alpha$-amylase has antimicrobial properties, suggesting handcycling evoked a transient upregulation in this aspect of mucosal immune defense [46], though the clinical relevance of these changes remains unknown.

The novelty of these findings is that they represent an ecologically valid appraisal of immunoendocrine responses of SCI athletes to a real-life, field-based exercise challenge. While the duration of the time trial was standardized, the exercise intensity was self-determined and represents the typical effort an individual would experience during training and/or competition. However, a limitation of this approach was that a standard relative exercise intensity was not employed. Furthermore, the participants represented a heterogeneous group; while some of the athletes were relatively new to the sport, others were very experienced handcyclists who frequently competed in both national and European races. This fact would most certainly influence both the absolute and relative exercise intensity adopted. Further, the fact that individuals achieved a very different time trial distance (range: 17.9-27.2 km) and associated volumes of work might, in part, help explain the wide variety of immunoendocrine responses observed at End-Ex. To our knowledge, there is presently no published literature examining the relationship between respiratory illness and immune function changes with exercise in athletes with SCI; however, given the present findings, this relationship may be of interest.

\section{CONCLUSIONS}

In summary, a $1 \mathrm{~h}$, self-paced handcycling time trial had a limited effect on mucosal immunity but elevated levels of circulating leukocytes. These changes appeared to be associated with an acute increase in SNS activity characterized by elevated $\alpha$-amylase activity. Collectively, these results suggest that handcycling can temporarily enhance certain immune indices in individuals with SCI. Given the increased incidence of infections in the SCI population, future research should assess how regular physical activity, as well as the level and completeness of the SCI, affect immunity and the incidence of infection. Such investigations could require athletes of a similar training status to exercise at a standard, relative exercise intensity in an attempt to elicit a more homogeneous response.

\section{ACKNOWLEDGMENTS}

\section{Author Contributions:}

Study concept and design: J. E. Allgrove, M. Chapman, P. M. Smith. Acquisition of data: J. E. Allgrove, M. Chapman, T. Christides, P. M. Smith.

Analysis and interpretation of data: J. E. Allgrove, P. M. Smith. Drafting of manuscript: J. E. Allgrove, T. Christides, P. M. Smith. Critical revision of manuscript for important intellectual content:

J. E. Allgrove, P. M. Smith.

Statistical analysis: J. E. Allgrove, P. M. Smith.

Administrative, technical, or material support: M. Chapman, T. Christides.

Financial Disclosures: The authors have declared that no competing interests exist.

Funding/Support: This material is the result of work supported with resources and the use of facilities at the University of Greenwich, Kent, United Kingdom.

Additional Contributions: The authors would like to acknowledge Amy Tanner, Christof Leicht, and James Fern for their assistance during data collection and Paul Dyer for his expert assistance with flow cytometry analysis.

Institutional Review: Prior to the study, all proposed methods and procedures gained institutional ethics approval and all volunteers provided written informed consent to participate.

Participant Follow-Up: The authors do not plan to inform participants of the publication of this study. However, participants have been encouraged to check the study Web site for updated publications.

\section{REFERENCES}

1. Nieman DC. Exercise and resistance to infection. Can J Physiol Pharmacol. 1998;76(5):573-80. [PMID:9839084] http://dx.doi.org/10.1139/y98-053

2. Pedersen BK, Bruunsgaard H. How physical exercise influences the establishment of infections. Sports Med. 1995; 19(6):393-400. [PMID:7676100] http://dx.doi.org/10.2165/00007256-199519060-00003

3. Gleeson M, Nieman DC, Pedersen BK. Exercise, nutrition and immune function. J Sports Sci. 2004;22(1):115-25. [PMID:14971437] http://dx.doi.org/10.1080/0264041031000140590

4. Nash MS. Immune dysfunction and illness susceptibility after spinal cord injury: an overview of probable causes, likely consequences, and potential treatments. J Spinal Cord Med. 2000;23(2):109-10. [PMID:10914351]

5. Nash MS. Known and plausible modulators of depressed immune functions following spinal cord injuries. J Spinal Cord Med. 2000;23(2):111-20. [PMID:10914352]

6. Campagnolo DI, Bartlett JA, Keller SE. Influence of neurological level on immune function following spinal cord injury: a review. J Spinal Cord Med. 2000;23(2):121-28. [PMID:10914353] 
7. Rogeri PS, Costa Rosa LF. Plasma glutamine concentration in spinal cord injured patients. Life Sci. 2005;77(19):2351-60. [PMID:16024049] http://dx.doi.org/10.1016/j.lfs.2004.09.050

8. Campagnolo DI, Dixon D, Schwartz J, Bartlett JA, Keller SE. Altered innate immunity following spinal cord injury. Spinal Cord. 2008;46(7):477-81. [PMID:18268516] http://dx.doi.org/10.1038/sc.2008.4

9. Johnson J, Wang MY. Spinal cord injury-induced immunodepression syndrome. Neurosurgery. 2008;63(6):13. [PMID:19057307] http://dx.doi.org/10.1227/01.NEU.0000313631.97644.D7

10. Campagnolo DI, Keller SE, DeLisa JA, Glick TJ, Sipski ML, Schleifer SJ. Alteration of immune system function in tetraplegics. A pilot study. Am J Phys Med Rehabil. 1994; 73(6):387-93. [PMID:7993612] http://dx.doi.org/10.1097/00002060-199411000-00003

11. Lynch AC, Palmer C, Lynch AC, Anthony A, Roake JA, Frye J, Frizelle FA. Nutritional and immune status following spinal cord injury: a case controlled study. Spinal Cord. 2002;40(12):627-30. [PMID:12483495] http://dx.doi.org/10.1038/sj.sc.3101382

12. Wu SK, Williams T. Factors influencing sports participation among athletes with spinal cord injury. Med Sci Sports Exerc. 2001;32:177-82. [PMID: 11224802] http://dx.doi.org/10.1097/00005768-200102000-00001

13. Dallmeijer AJ, Zentgraaff ID, Zijp NI, van der Woude LH. Submaximal physical strain and peak performance in handcycling versus handrim wheelchair propulsion. Spinal Cord. 2004;42(2):91-98. [PMID:14765141] http://dx.doi.org/10.1038/sj.sc.3101566

14. Valent LJ, Dallmeijer AJ, Houdijk H, Slootman HJ, Post MW, van der Woude LH. Influence of hand cycling on physical capacity in the rehabilitation of persons with a spinal cord injury: a longitudinal cohort study. Arch Phys Med Rehabil. 2008;89(6):1016-22. [PMID:18503794] http://dx.doi.org/10.1016/j.apmr.2007.10.034

15. Abel T, Kröner M, Rojas Vega S, Peters C, Klose C, Platen P. Energy expenditure in wheelchair racing and handbiking - a basis for prevention of cardiovascular diseases in those with disabilities. Eur J Cardiovasc Prev Rehabil. 2003;10(5): 371-76. [PMID:14663299] http://dx.doi.org/10.1097/01.hjr.0000096542.30533.59

16. Sawka MN. Physiology of upper body exercise. Exerc Sport Sci Rev. 1986;14:175-211. [PMID:3525185] http://dx.doi.org/10.1249/00003677-198600140-00009

17. Nash MS. Immune responses to nervous system decentralization and exercise in quadriplegia. Med Sci Sports Exerc. 1994;73:184-92. [PMID: 8164533]

18. Kawashima N, Nakazawa K, Ishii N, Akai M, Yano H. Potential impact of orthotic gait exercise on natural killer cell activities in thoracic level of spinal cord-injured patients. Spinal Cord. 2004;42(7):420-24.

\section{[PMID:15124001]}

http://dx.doi.org/10.1038/sj.sc.3101625

19. Furusawa K, Tajima F, Tanaka Y, Ide M, Ogata H. Shortterm attenuation of natural killer cell cytotoxic activity in wheelchair marathoners with paraplegia. Arch Phys Med Rehabil. 1998;79(9):1116-21. [PMID:9749694] http://dx.doi.org/10.1016/S0003-9993(98)90181-2

20. Ueta M, Furusawa K, Takahashi M, Akatsu Y, Nakamura T, Tajima F. Attenuation of natural killer cell activity during 2-h exercise in individuals with spinal cord injuries. Spinal Cord. 2008;46(1):26-32. [PMID:17387314] http://dx.doi.org/10.1038/sj.sc.3102054

21. Gleeson M, McDonald WA, Pyne DB, Cripps AW, Francis JL, Fricker PA, Clancy RL. Salivary IgA levels and infection risk in elite swimmers. Med Sci Sports Exerc. 1999; 31(1):67-73. [PMID:9927012] http://dx.doi.org/10.1097/00005768-199901000-00012

22. Fahlman MM, Engels HJ. Mucosal IgA and URTI in American college football players: a year longitudinal study. Med Sci Sports Exerc. 2005;37(3):374-80. [PMID:15741834] http://dx.doi.org/10.1249/01.MSS.0000155432.67020.88

23. Bishop NC, Gleeson M. Acute and chronic effects of exercise on markers of mucosal immunity. Front Biosci. 2009; 14:4444-56. [PMID:19273362]

http://dx.doi.org/10.2741/3540

24. Klentrou P, Cieslak T, MacNeil M, Vintinner A, Plyley M. Effect of moderate exercise on salivary immunoglobulin A and infection risk in humans. Eur J Appl Physiol. 2002; 87(2):153-58. [PMID:12070626] http://dx.doi.org/10.1007/s00421-002-0609-1

25. Leicht CA, Bishop NC, Goosey-Tolfrey VL. Mucosal immune responses to treadmill exercise in elite wheelchair athletes. Med Sci Sports Exerc. 2011;43(8):1414-21.

[PMID:21228725]

http://dx.doi.org/10.1249/MSS.0b013e31820ac959

26. Schwab KO, Heubel G, Bartels H. Free epinephrine, norepinephrine and dopamine in saliva and plasma of healthy adults. Eur J Clin Chem Clin Biochem. 1992;30(9):541-44. [PMID:1457617]

27. Chatterton RT Jr, Vogelsong KM, Lu YC, Ellman AB, Hudgens GA. Salivary alpha-amylase as a measure of endogenous adrenergic activity. Clin Physiol. 1996;16(4): 433-48. [PMID:8842578] http://dx.doi.org/10.1111/j.1475-097X.1996.tb00731.x

28. Tomasi TB, Trudeau FB, Czerwinski D, Erredge S. Immune parameters in athletes before and after strenuous exercise. J Clin Immunol. 1982;2(3):173-78.

[PMID:6981653]

http://dx.doi.org/10.1007/BF00915219

29. Nieman DC, Henson DA, Fagoaga OR, Utter AC, Vinci DM, Davis JM, Nehlsen-Cannarella SL. Change in salivary IgA following a competitive marathon race. Int J Sports 
Med. 2002;23(1):69-75. [PMID:11774070]

http://dx.doi.org/10.1055/s-2002-19375

30. Allgrove JE, Gomes E, Hough J, Gleeson M. Effects of exercise intensity on salivary antimicrobial proteins and markers of stress in active men. J Sports Sci. 2008;26(6): 653-61. [PMID:18344136] http://dx.doi.org/10.1080/02640410701716790

31. Nehlsen-Cannarella SL, Nieman DC, Fagoaga OR, Kelln WJ, Henson DA, Shannon M, Davis JM. Saliva immunoglobulins in elite women rowers. Eur J Appl Physiol. 2000; 81(3):222-28. [PMID:10638381] http://dx.doi.org/10.1007/s004210050034

32. Allgrove JE, Geneen L, Latif S, Gleeson M. Influence of a fed or fasted state on the s-IgA response to prolonged cycling in active men and women. Int J Sport Nutr Exerc Metab. 2009;19(3):209-21. [PMID:19574610]

33. Sari-Sarraf V, Reilly T, Doran DA, Atkinson G. The effects of single and repeated bouts of soccer-specific exercise on salivary IgA. Arch Oral Biol. 2007;52(6):526-32.

[PMID:17210115] http://dx.doi.org/10.1016/j.archoralbio.2006.11.016

34. Proctor GB, Garrett JR, Carpenter GH, Ebersole LE. Salivary secretion of immunoglobulin A by submandibular glands in response to autonomimetic infusions in anaesthetised rats. J Neuroimmunol. 2003;136(1-2):17-24.

[PMID:12620639]

http://dx.doi.org/10.1016/S0165-5728(02)00466-6

35. Saxon A, Stevens RH, Ramer SJ, Clements PJ, Yu DT. Glucocorticoids administered in vivo inhibit human suppressor $\mathrm{T}$ lymphocyte function and diminish B lymphocyte responsiveness in in vitro immunoglobulin synthesis. J Clin Invest. 1978;61(4):922-30. [PMID:96133] http://dx.doi.org/10.1172/JCI109017

36. Walsh NP, Laing SJ, Oliver SJ, Montague JC, Walters R, Bilzon JL. Saliva parameters as potential indices of hydration status during acute dehydration. Med Sci Sports Exerc. 2004;36(9):1535-42. [PMID:15354035] http://dx.doi.org/10.1249/01.MSS.0000139797.26760.06

37. Kakanis MW, Peake J, Brenu EW, Simmonds M, Gray B, Hooper SL, Marshall-Gradisnik SM. The open window of susceptibility to infection after acute exercise in healthy young male elite athletes. Exerc Immunol Rev. 2010; 16:119-37. [PMID:20839496]

38. Nieman DC. Is infection risk linked to exercise workload? Med Sci Sports Exerc. 2000;32(7 Suppl):S406-11. [PMID:10910297] http://dx.doi.org/10.1097/00005768-200007001-00005

39. McCarthy DA, Macdonald I, Grant MM, Marbut M, Watling M, Nicholson S, Deeks JJ, Wade AJ, Perry JD. Studies on the immediate and delayed leucocytosis elicited by brief (30-min) strenuous exercise. Eur J Appl Physiol Occup Physiol. 1992;64(6):513-17. [PMID:1618188]

http://dx.doi.org/10.1007/BF00843760

40. Gleeson M. Immune function in sport and exercise. J Appl Physiol. 2007;103(2):693-99. [PMID:17303714] http://dx.doi.org/10.1152/japplphysiol.00008.2007

41. Nieman DC, Nehlsen-Cannarella SL, Fagoaga OR, Henson DA, Shannon M, Hjertman JM, Schmitt RL, Bolton MR, Austin MD, Schilling BK, Thorpe R. Immune function in female elite rowers and non-athletes. Br J Sports Med. 2000;34(3):181-87. [PMID:10854017] http://dx.doi.org/10.1136/bjsm.34.3.181

42. Robson PJ, Blannin AK, Walsh NP, Bishop N, Gleeson M. The effect of an acute period of intense interval training on human neutrophil function and plasma glutamine in endurance-trained male runners. J Physiol. 1999;515:84-85.

43. Viru A, Viru M. Cortisol-essential adaptation hormone in exercise. Int J Sports Med. 2004;25(6):461-64. [PMID:15346236] http://dx.doi.org/10.1055/s-2004-821068

44. Harris A, Marquis P, Eriksen HR, Grant I, Corbett R, Lie SA. Ursin, H. Diurnal rhythm in British Antarctic personnel. Rural Remote Health. 2010;10:1-12.

45. Laing SJ, Jackson AR, Walters R, Lloyd-Jones E, Whitham M, Maassen N, Walsh NP. Human blood neutrophil responses to prolonged exercise with and without a thermal clamp. J Appl Physiol. 2008;104(1):20-26. [PMID:17901240] http://dx.doi.org/10.1152/japplphysiol.00792.2007

46. Li TL, Gleeson M. The effect of single and repeated bouts of prolonged cycling and circadian variation on saliva flow rate, immunoglobulin A and $\alpha$-amylase responses. J Sports Sci. 2004;22(11-12):1015-24. [PMID:15801495] http://dx.doi.org/10.1080/02640410410001716733

Submitted for publication June 9, 2011. Accepted in revised form November 4, 2011.

This article and any supplementary material should be cited as follows:

Allgrove JE, Chapman M, Christides T, Smith PM. Immunoendocrine responses of male spinal cord injured athletes to 1-hour self-paced exercise: Pilot study. J Rehabil Res Dev. 2012;49(6):925-34.

http://dx.doi.org/10.1682/JRRD.2011.06.0105

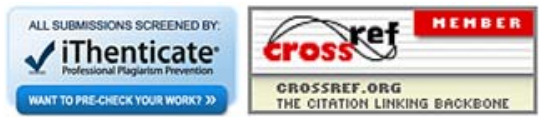


